\title{
Temperature estimation of focused ultrasound exposures for stroke treatment ${ }^{*}$
}

\author{
${ }^{1}$ MEDSONIC LTD, Limassol, Cyprus; \\ ${ }^{2}$ Frederick University Cyprus, Limassol, Cyprus; \\ ${ }^{3}$ City University, London, UK. \\ Email: venedik@cytanet.com.cy
}

Venediktos Hadjisavvas $^{1,3}$, Christakis Damianou ${ }^{1,2}$

Received 12 March 2011; revised 28 March 2011; accepted 26 April 2011.

\section{ABSTRACT}

Introduction: in this paper a simulation model for predicting the temperature during the application of focused ultrasound (FUS) for stroke treatment using pulsed ultrasound is presented. Materials and methods: a single element spherically focused transducer of $5 \mathrm{~cm}$ diameter, focusing at $10 \mathrm{~cm}$ and operating at either $0.5 \mathrm{MHz}$ or $1 \mathrm{MHz}$ was considered. The power field was estimated using the Khokhlov-Zabolotskaya-Kuznetzov (KZK) model. The temperature was estimated using the bioheat equation. The goal was to extract the acoustic parameters (frequency, power, and duty factor) that maintain a temperature increase of less than $1^{\circ} \mathrm{C}$ during the application of a pulse ultrasound protocol. Results: it was found that the temperature change increases linearly with duty factor. The higher the power, the lower the duty factor needed to keep the temperature change to the safe limit of $1^{\circ} \mathrm{C}$. The higher the frequency the lower the duty factor needed to keep the temperature change to the safe limit of $1^{\circ} \mathrm{C}$. Finally, the shallow the target, the lower the duty factor needed to keep the temperature change to the safe limit of $1^{\circ} \mathrm{C}$. The simulation model was tested in brain tissue during the application of pulse ultrasound and the measured temperature was in close agreement with the simulated temperature. Conclusions: This simulation model is considered to be very useful tool for providing acoustic parameters (frequency, power, and duty factor) during the application of pulsed ultrasound at various depths in tissue so that a safe temperature is maintained during the treatment. This model will be tested eventually during stroke clinical trials.

${ }^{*}$ This work was supported by the Research Promotion Foundation (RPF) of Cyprus and the European regional development structure

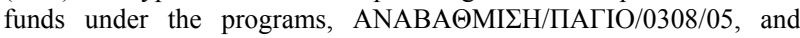
EПIXЕIPH $\Sigma$ EI $\Sigma /$ ЕАРM/0308/
Keywords: Ultrasound; Stroke; Temperature

\section{INTRODUCTION}

Ultrasound can be used for noninvasive treatment in combination with the thrombolytic drug to dissolve clots located deep in the brain without destroying the surrounding tissue [1-5]. High intensity focused ultrasound (HIFU) is being used today primarily to thermally destroy tissue $[2,3]$. Heat produced at the focal point is very high in a very short period of time. As a result, temperature elevations in the exposed area can ablate the tissue $[8,9]$.

During the past few years, treatment of ischemic stroke using ultrasound has received great attention [10-15]. Most previous studies have used unfocused ultrasound at very low intensities. Several experimental studies have been performed to investigate the effectiveness of sonothrombolysis with, and without, thrombolytic drugs (such as Recombinant Tissue-Type Plasminogen Activator) [1,10-15].

Recently, experiments have demonstrated the ability of HIFU used for noninvasive procedures to dissolve thrombus [2,3,18-20]. Maxwell et al. reported that histotripsy therapy using short, HIFU pulses can cause mechanical breakdown of targeted soft tissue by acoustic cavitation, which is guided by real-time ultrasound imaging [2,3]. Moreover, a study has shown the effectiveness of pursed HIFU in vitro and in vivo to enhance thrombolysis induced by tissue plasminogen activator (tPA) $[17,18]$.

The mode of action of ultrasound during sonothrombolysis is mechanical. Therefore temperature elevation is the key safety issue in treating patients with ischemic stroke. It was shown that when the temperature rises to $43^{\circ} \mathrm{C}$ and above, enough thermal dose is produced to destroy human tissue [19]. In order to avoid any unwanted effects on human tissue caused by temperature 
rise, a maximum temperature limit was set to $1^{\circ} \mathrm{C}$ in this simulation study.

The aim of this study was to control temperature elevation in order to avoid heating of the brain during sonothrombolysis. A computer model [20] was used to estimate the temperature elevation, based on the transducer characteristics (frequency, diameter, degree of focusing), treatment protocol (pulse duration, duty factor, acoustical power), and the anatomical site (depth). A single element spherically focused transducer of $5 \mathrm{~cm}$ diameter, focusing at $10 \mathrm{~cm}$ and operating at either 0.5 $\mathrm{MHz}$ or $1 \mathrm{MHz}$ was considered. For all simulations, the focus was set at either $1 \mathrm{~cm}$ or $2.5 \mathrm{~cm}$ deep into the tissue. The goal was to extract the acoustic parameters (frequency, power, and duty factor), that maintains a temperature increase of less than $1^{\circ} \mathrm{C}$ during the application of pulsed ultrasound.

\section{MATERIALS AND METHODS}

\subsection{Simulation Model}

Figure 1 shows a diagram of the applied sonication protocol. Pulse Repetition Period (PRP) is the amount of time from the start of one pulse to the start of the next pulse. It includes both the sound "ON" time and "OFF" time. PRP of $1 \mathrm{~ms}$ and $1 \mathrm{~s}$ were used in this simulation study. Duty factor (DF) is the proportion of time that the ultrasound transducer is actually producing sound energy. It is the ratio between pulse duration (sound ON time) and PRP (sound ON plus sound OFF time). The DF ranges from $2 \%$ to $100 \%$ in this sonication time. The sonication period used in all simulations and experiments are $60 \mathrm{~s}$ and $120 \mathrm{~s}$.

The power field was estimated using the KZK model [20]. The temperature vs time history was obtained by solving the bio-heat equation proposed by Pennes numerically [22]. The explicit form of this equation is given by:

$$
p_{t} c_{t} \frac{\partial T}{\partial t}=k \nabla^{2} T+w_{b} c_{b}\left(T-T_{a}\right)+Q_{p}+Q_{m}
$$

where $\rho_{t}$ is the density of the tissue, $c_{t}$ is the specific heat of the tissue, $T$ is the temperature of the tissue, $t$ is the time, $w_{b}$ is the blood perfusion rate, $c_{b}$ is the specific heat of the blood, $T_{a}$ is the arterial blood temperature, $k$ is the thermal conductivity of the tissue, $Q_{p}$ is the ultrasonic power deposition rate, and $Q_{m}$ is the local metabolic rate which was neglected in the computer simulations. The first term in the above equation represent the temperature rise with respect to time, the second term represents the conduction effect which tends to decrease the temperature, the third term represents the convection effect due to blood which decreases the temperature, and the fourth term represents the power absorbed due to the

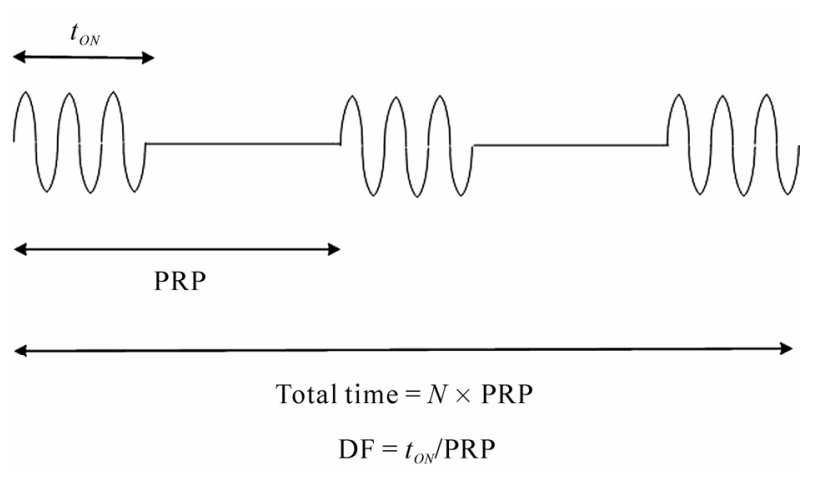

Figure 1. Timing diagram explaining PRP, DF, and total time.

ultrasonic source which increases the temperature. The blood perfusion is modeled as a uniform heat-sink with blood supplied by vessels into the tissue volume at body temperature $T_{a}$ and exiting at tissue temperature $T$. All units and values of the above parameters are given in Table 1. The temperature distribution at a given time was observed by solving the bio-heat differential equation using a finite difference technique.

\subsection{Temperature Measurement}

A data acquisition board (6251 DAQ, National Instruments, Texas, USA) was used to measure the temperature. An analogue input of the board was used to capture the temperature. An Omega M2813-1205 (OMEGA Engineering, INC. Stamford, Connecticut, USA) thermocouple-to-analogue connector was used to give analogue output (1 mv per degree). This was entered in to the data acquisition card and read by custom-made software written in MatLab (The Mathworks Inc., Natick, MA). A $50 \mu \mathrm{m}$ thermocouple (Omega engineering INC, Connecticut, USA) was placed in the thrombus in order to measure temperature elevation at the focal point (clot). During the experiments, temperature was recorded every $0.2 \mathrm{~s}$.

\subsection{In Vitro Experiments}

Experiments were carried out to investigate the accuracy of the simulation model. Figure 2 shows the HIFU system, which consists of a signal generator and RF amplifier (100 W, JJ\&A Instruments, USA), and a spherically shaped transducer made from piezoelectric ceramic of low magnetic susceptibility (Piezotechnologies, Lebanon, IN, USA). Two transducers were used operating either at $0.5 \mathrm{MHz}$, or $1 \mathrm{MHz}$. Both transducers had a focal length of $10 \mathrm{~cm}$ and diameter of $5 \mathrm{~cm}$. The transducer is mounted on the 3D positioning device (MEDSONIC, Limassol, Cyprus). Blood clots were obtained by natural coagulation of animal blood samples from healthy cows. Blood was drawn into small containers and placed in a $37^{\circ} \mathrm{C}$ water bath for $3 \mathrm{~h}$ and storing the clots in a $5^{\circ} \mathrm{C}$ refrigerator 
Table 1. Parameters used for the temperature vs. time simulations.

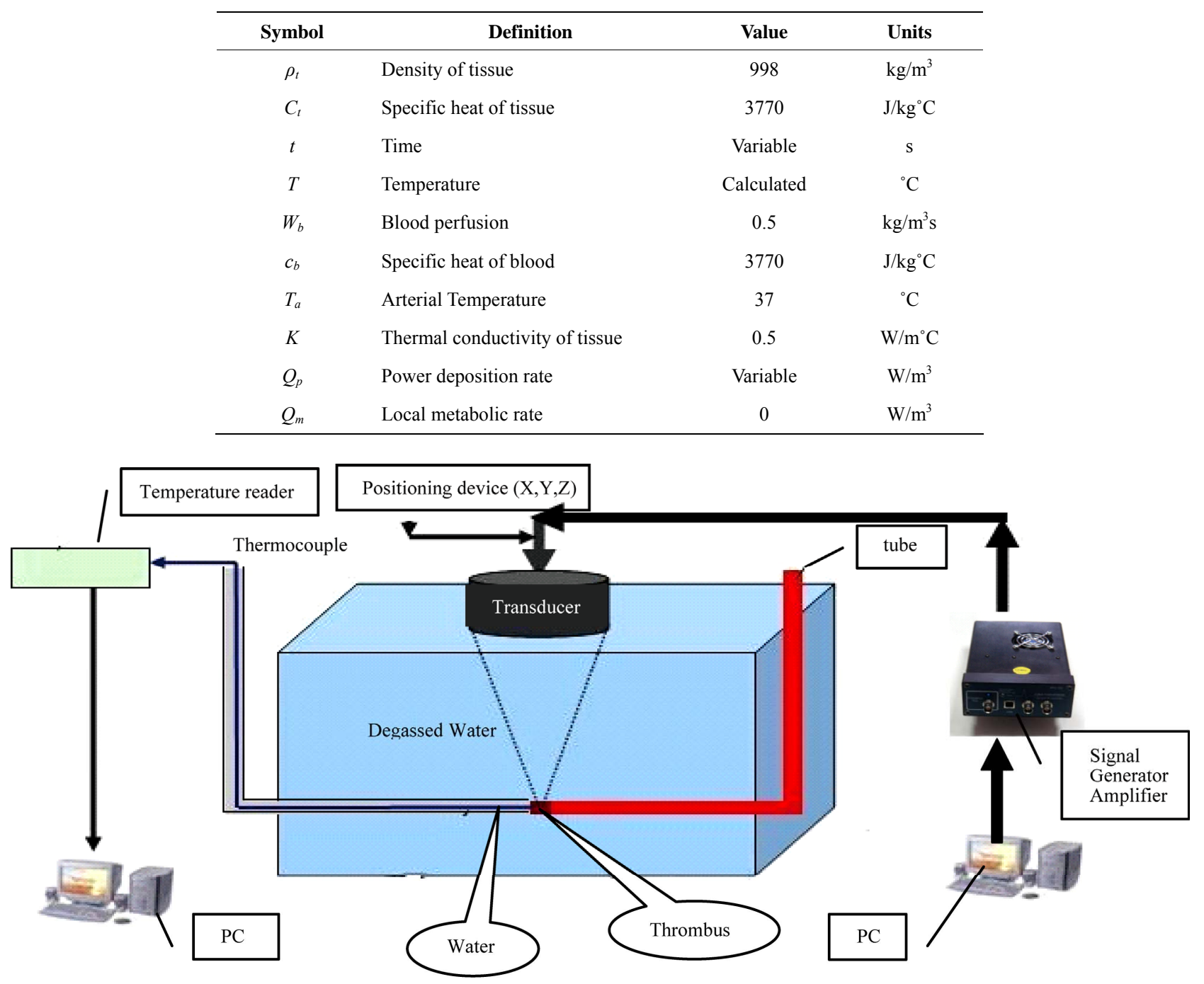

Figure 2. Schematic diagram of the MR-guided FUS system.

for at least $72 \mathrm{~h}$ before use in the experiments to allow complete clot retraction [22]. The blood clot was placed inside the silicon tube (Figure 2). A thermocouple was inserted in the middle of the clot to monitor temperature elevation.

\section{RESULTS}

The accuracy of the simulation model was tested on thrombus which is placed in the silicone tube which is immersed in a water bath. Pulsed ultrasound was applied with pulse repetition period of $1 \mathrm{~s}$ using the $1 \mathrm{MHz}$ transducer. Figure 3 shows simulated and experimental temperature measured in the thrombus. The experimental and simulated results agree well, indicating that the simulation model can be used to give guidelines for various sonothrombolysis protocols.

Figure 4 shows the simulated temperature elevation at

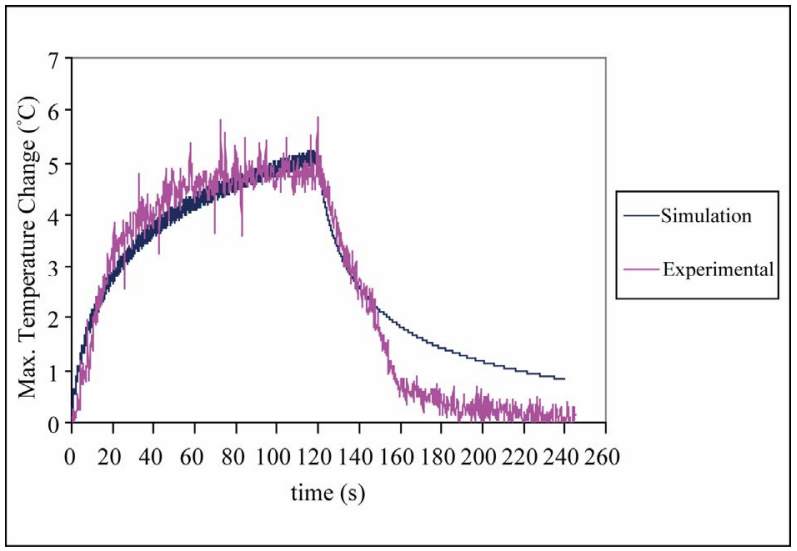

Figure 3. Simulated and experimental temperature vs. time with duty Factor $=5 \%$, Power $=20 \mathrm{~W}, f=1 \mathrm{MHz}$, Radius of Curvature $=10 \mathrm{~cm}$, Transducer Diameter $=5 \mathrm{~cm}$, Focal Depth $=$ $1 \mathrm{~cm}, \mathrm{PRP}=1 \mathrm{~s}$. 


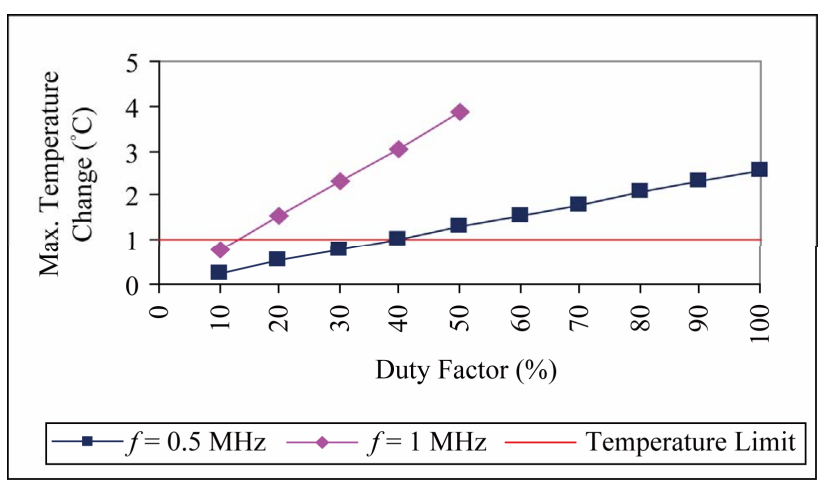

(a)

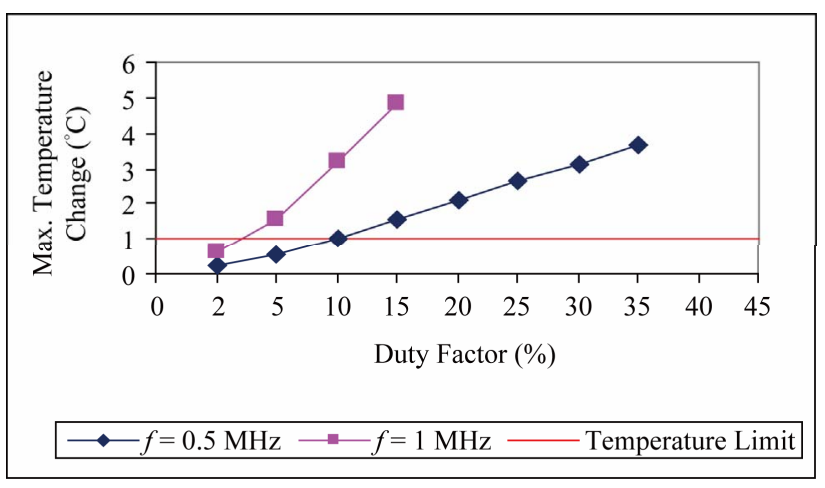

(c)

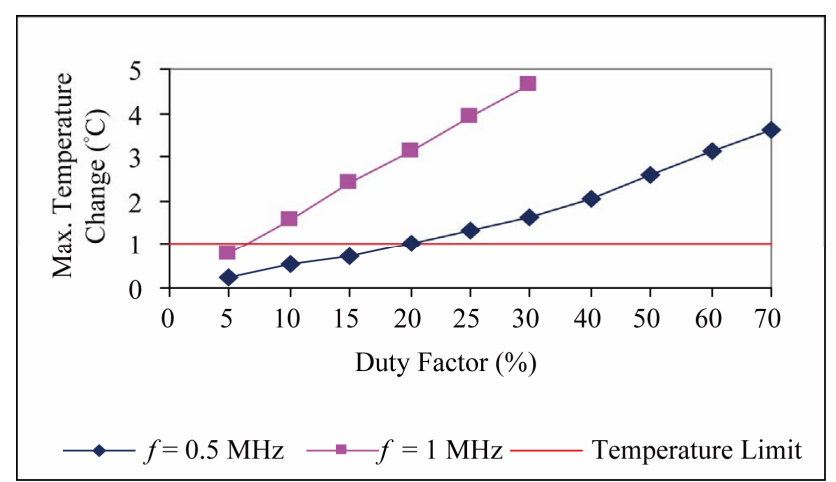

(b)

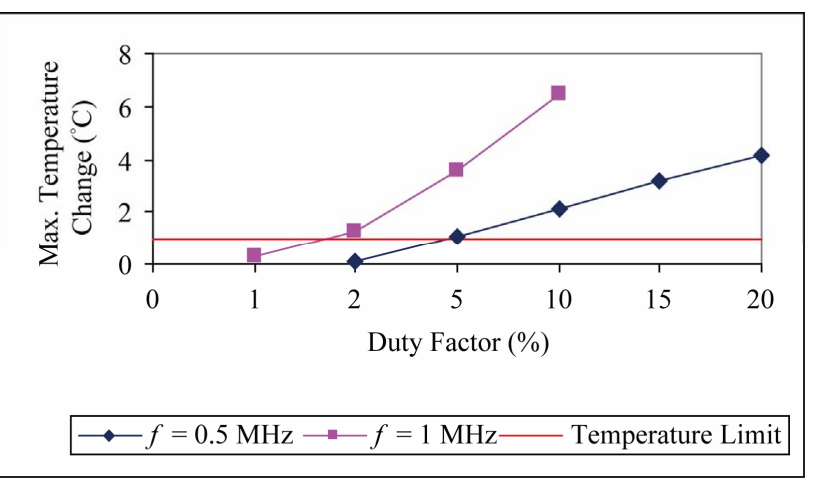

(d)

Figure 4. Temperature vs duty factor for different power and FD=2.5 cm. (a) $2.5 \mathrm{~W}$; (b) $5 \mathrm{~W}$; (c) $10 \mathrm{~W}$; (d) $20 \mathrm{~W}$.

frequencies of $0.5 \mathrm{MHz}$ and $1 \mathrm{MHz}$ with a focal depth (FD) of $2.5 \mathrm{~cm}$. The effect of duty factor on temperature elevation was investigated using power of (a) $2.5 \mathrm{~W}$, (b) $5 \mathrm{~W}$, (c) $10 \mathrm{~W}$, and (d) $20 \mathrm{~W}$. The maximum temperature at steady state increased linearly with duty factor. With frequency of $1 \mathrm{MHz}$, the duty factor needed to maintain safe temperature is lower for the same power.

Figure 5 summarizes the effect of applied acoustic power on the duty factor which establishes safe temperature at frequency of $0.5 \mathrm{MHz}$. Acoustical power is inversely related to duty factor. The higher the power, the lower the duty factor.

Figure 6 shows the simulated temperature elevation at frequency of $0.5 \mathrm{MHz}$ and $1 \mathrm{MHz}$ but with a focal depth of $1 \mathrm{~cm}$ using pulse repetition period of $1 \mathrm{~s}$. The trend of temperature is similar as with the focal depth of $2.5 \mathrm{~cm}$. With focal depth of $1 \mathrm{~cm}$, the temperature increase is higher and therefore less duty factor required maintaining safe temperature.

The effect of the applied acoustical power on the temperature elevation is shown in Figure 7. Focal depth of $1 \mathrm{~cm}$ and $2.5 \mathrm{~cm}, \mathrm{PRP}=1 \mathrm{~s}$, and a frequency of 0.5 $\mathrm{MHz}$ and $1 \mathrm{MHz}$ were used. With $0.5 \mathrm{MHz}$ the duty factor needed for different power is almost the same regardless the focal depth, either with $1 \mathrm{~cm}$ or $2.5 \mathrm{~cm}$. When the frequency is increased to $1 \mathrm{MHz}$, safe tem-

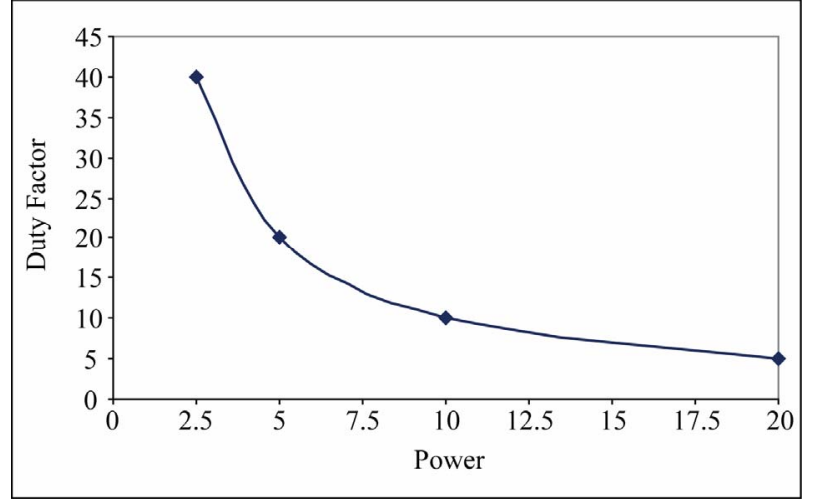

Figure 5. Duty Factor that establishes safe temperature vs. Power, $f=0.5 \mathrm{MHz}$, Radius of Curvature $=10 \mathrm{~cm}$, Transducer Diameter $=5 \mathrm{~cm}$, Focal Depth $=2.5 \mathrm{~cm}, \mathrm{PRP}=1 \mathrm{~s}$.

perature cannot be achieved at any power $(5 \mathrm{~W}, 10 \mathrm{~W}$, and $20 \mathrm{~W}$ ) except when $2.5 \mathrm{~W}$ is used. Temperature limit was reached at $10 \%$ for $2.5 \mathrm{~W}$ and at focal depth of $1 \mathrm{~cm}$ where $14 \%$ is needed at focal depth of $2.5 \mathrm{~cm}$. The duty factor to be used that maintains safe temperature is higher for lower power.

Figure 8 shows simulation results for the safe temperature using a $1 \mathrm{MHz}$ transducer. Two different focal depths (FD) were used: $1 \mathrm{~cm}$ and $2.5 \mathrm{~cm}$. The effect of duty factor on the safe temperature was investigated using 


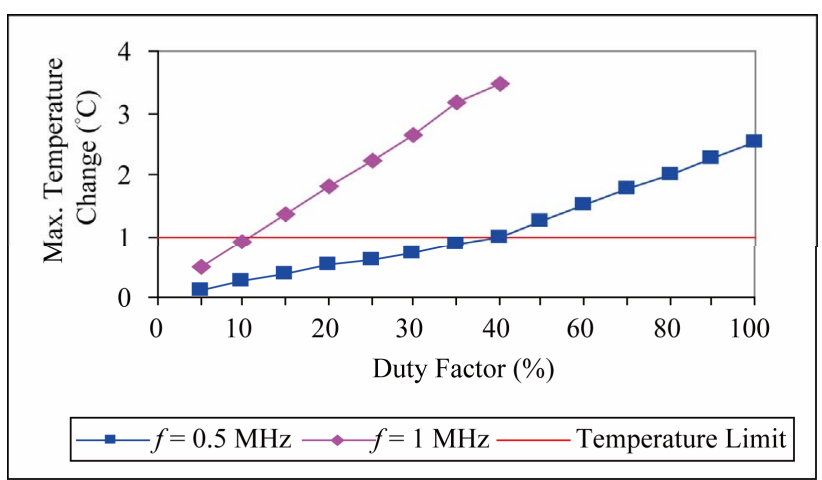

(a)

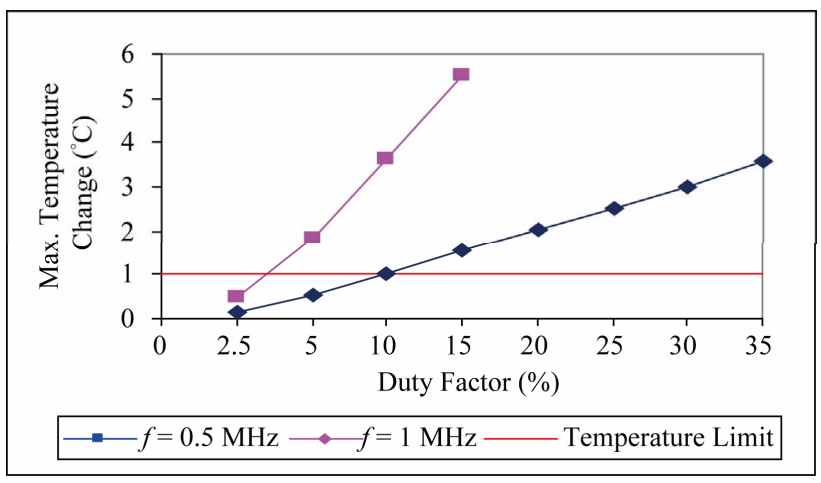

(c)

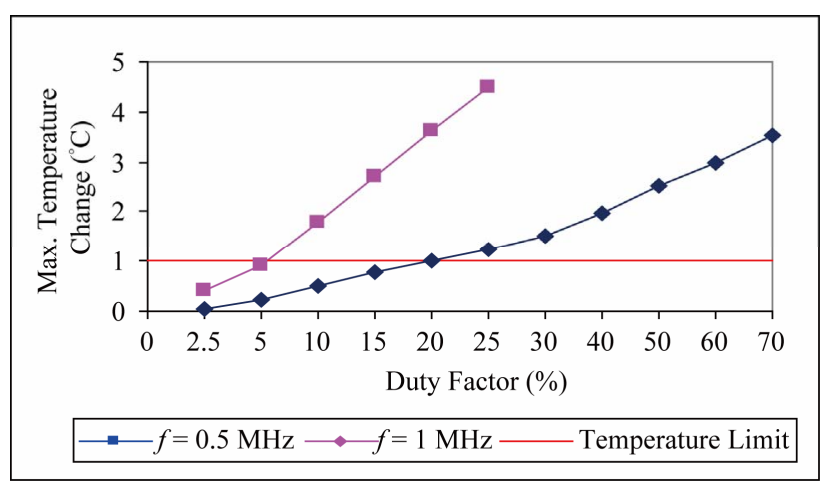

(b)

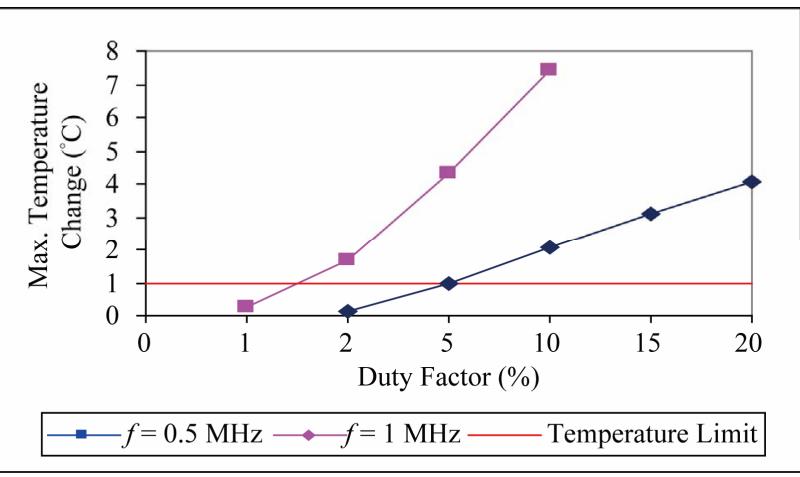

(d)

Figure 6. Temperature vs Duty Factor with focal depth of $1 \mathrm{~cm}$ for different Power. (a) $2.5 \mathrm{~W}$; (b) $5 \mathrm{~W}$; (c) $10 \mathrm{~W}$; (d) $20 \mathrm{~W}$.

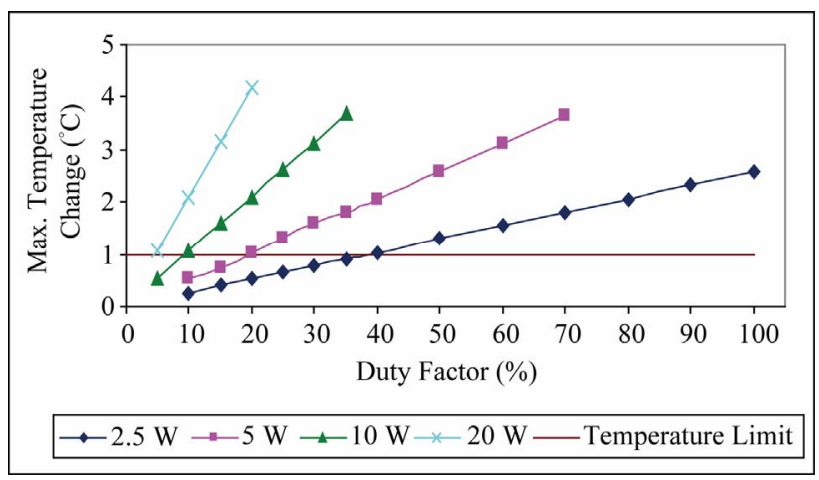

(a)

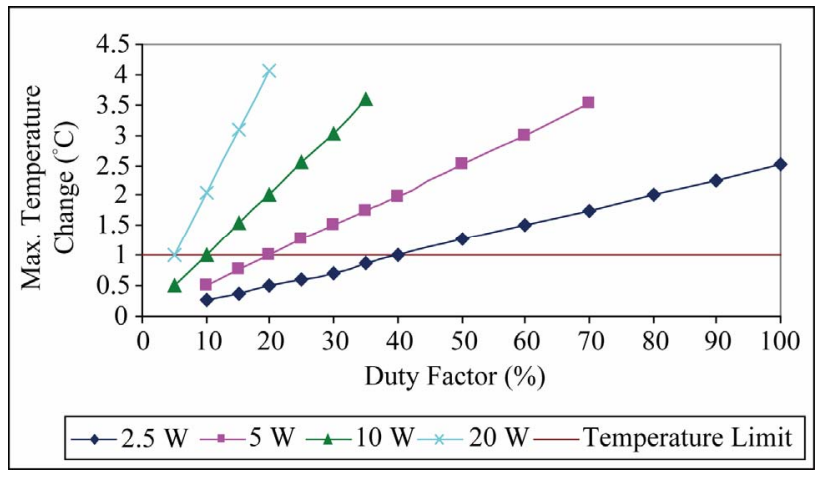

(c)

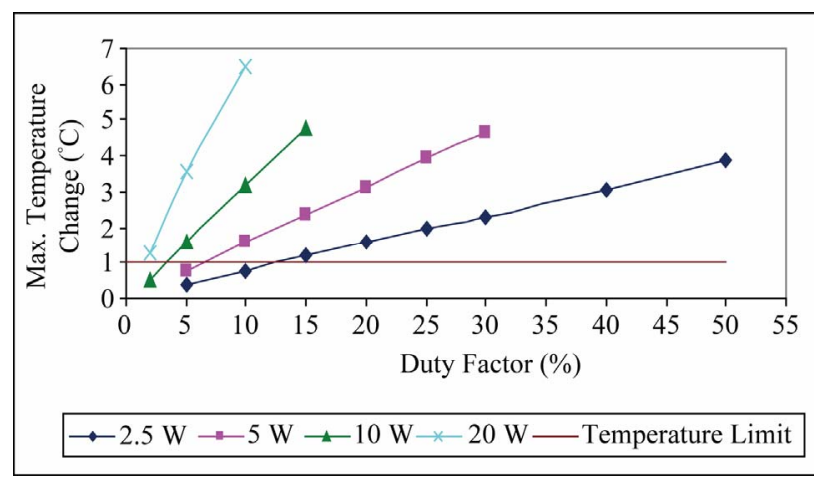

(b)

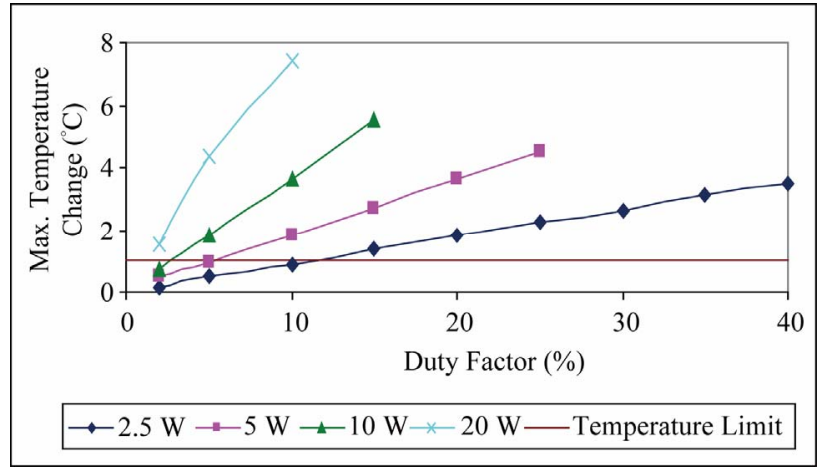

(d)

Figure 7. Temperature vs Duty Factor. (a) $f=0.5 \mathrm{MHz} ; \mathrm{FD}=2.5 \mathrm{~cm}$; (b) $f=1 \mathrm{MHz}, \mathrm{FD}=2.5 \mathrm{~cm}$; (c) $f=0.5 \mathrm{MHz}, \mathrm{FD}=1 \mathrm{~cm}$; (d) $f=1$ $\mathrm{MHz}, \mathrm{FD}=1 \mathrm{~cm}$. 


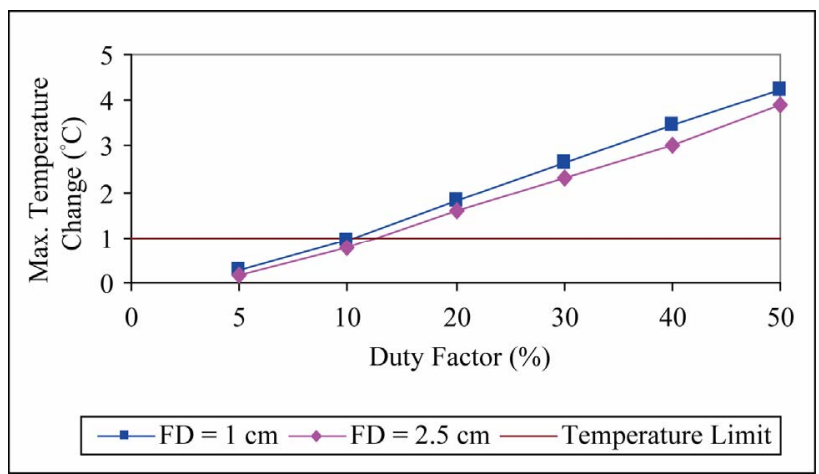

(a)

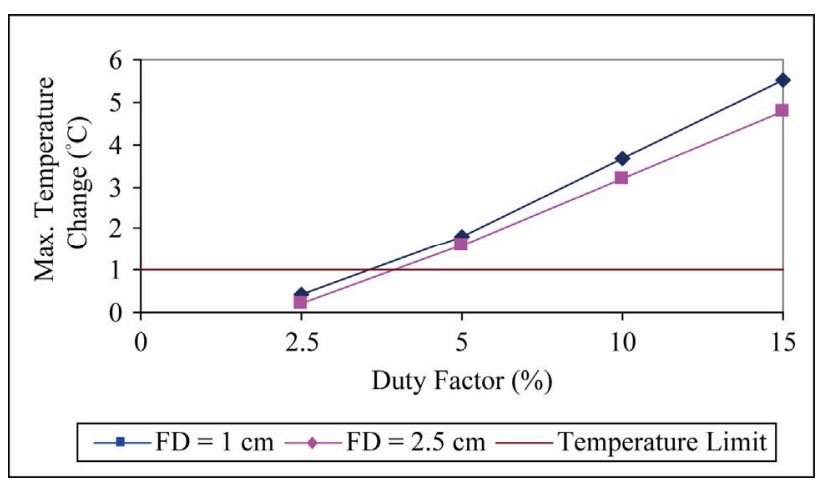

(c)

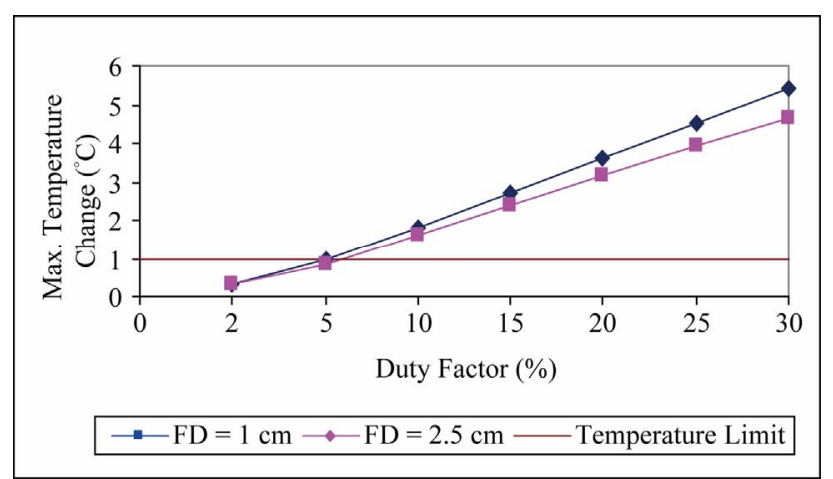

(b)

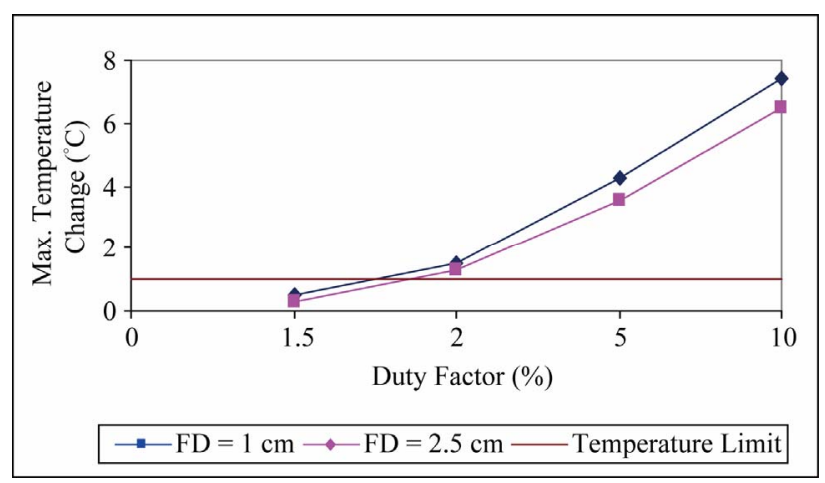

(d)

Figure 8. Temperature vs duty factor for different power and $f=1 \mathrm{MHz}$. (a) $2.5 \mathrm{~W}$; (b) $5 \mathrm{~W}$; (c) $10 \mathrm{~W}$; (d) $20 \mathrm{~W}$.

power of (a) $2.5 \mathrm{~W}$, (b) $5 \mathrm{~W}$, (c) $10 \mathrm{~W}$, and (d) $20 \mathrm{~W}$. When the focal depth is close to the surface $(1 \mathrm{~cm}$ deep) the intensity is higher compared to that at $2.5 \mathrm{~cm}$ and therefore a lower duty factor is needed to reach the temperature limit. Figure 9 shows the same results as in Figure 8 but at a frequency of $0.5 \mathrm{MHz}$. Using a frequency of $0.5 \mathrm{MHz}$, the temperature limit was reached at $\mathrm{DF}=40 \%, 20 \%, 10 \%$, and $5 \%$ for power of $2.5 \mathrm{~W}, 5 \mathrm{~W}$, $10 \mathrm{~W}$, and $20 \mathrm{~W}$ respectively for both focal depth $(1 \mathrm{~cm}$ or $2.5 \mathrm{~cm})$.

\section{DISCUSSION}

The simulation results provide a good indicator of temperature elevation at the focal point. The temperature increases as a function of applied power with the rate of increase dependent upon the duty factor and frequency. The temperature elevation was simulated for different power and duty factor. These results will guide us towards the best sonication system in a faster and more appropriate way than using extensive animal experiments.

It was found that the temperature increases linearly with duty factor. The higher the power the lower the duty factor needed to keep the temperature change within the safe limit of $1^{\circ} \mathrm{C}$. Also, the higher the frequency the lower the duty factor needed to keep the temperature change to the safe limit of $1^{\circ} \mathrm{C}$. Finally, the deeper the target, the higher the duty factor allowed to keep the temperature changes to the safe limit of $1{ }^{\circ} \mathrm{C}$.

The simulation results agree well with the experimental results. However, further experiments either in vitro or in vivo will require, verifying the current simulation results. Most of the previews experimental studies have demonstrated temperature elevation above $3^{\circ} \mathrm{C}[23,24]$. If this temperature elevation can not be controlled will cause unwanted tissue damage during sonication [25]. There are also cases when either low intensities or low frequencies are applied and temperature elevation drops below the $3^{\circ} \mathrm{C}[23,26]$. We have shown that temperature elevation can be controlled and kept within the safe region by adjusting various parameters such as the duty factor, the operating frequency, and the acoustic power.

The simulation results prove that longer duty factors will increase the temperature elevation. Figure 6 shows that the temperature increases with increasing duty factor. This happens because greater duty factors allow less time for the tissue to cool off, causing the temperature to rise higher than the allowed maximum limit of $1^{\circ} \mathrm{C}$.

Temperatures also increase faster when the focal depth is $1 \mathrm{~cm}$ compared to $2.5 \mathrm{~cm}$ deep in the tissue, or more slowly when it is $2.5 \mathrm{~cm}$ deep in the tissue. A comparison of the effect of frequency in Figures 4 and 5 indicate 


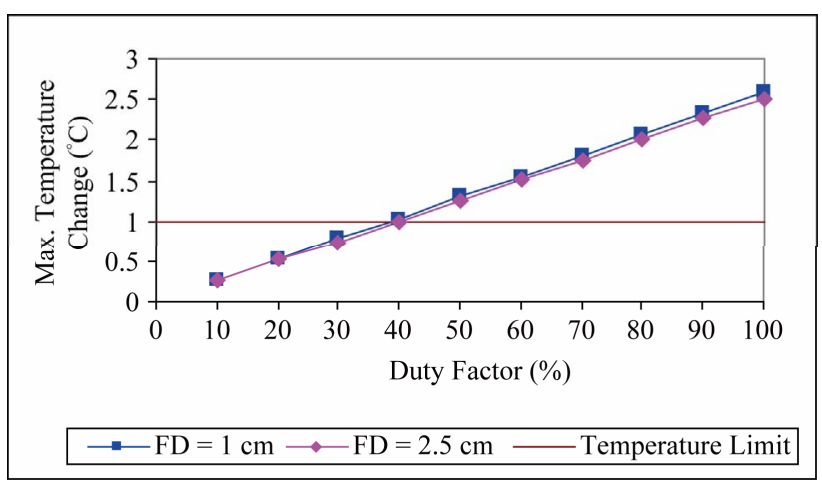

(a)

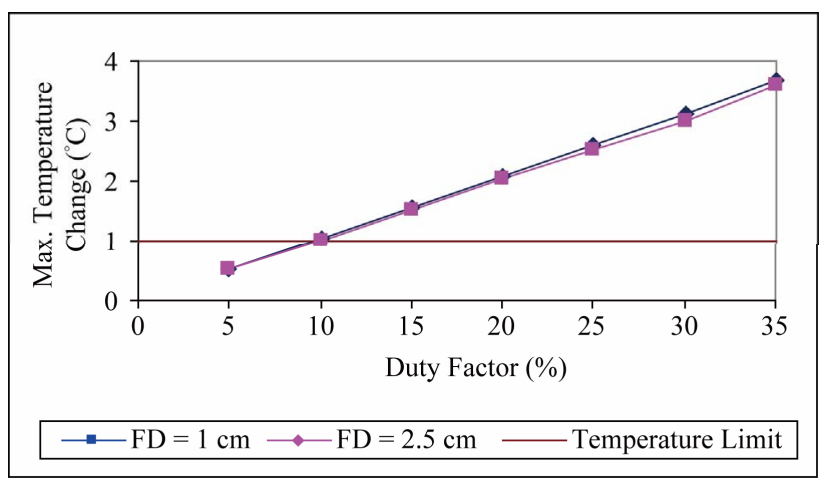

(c)

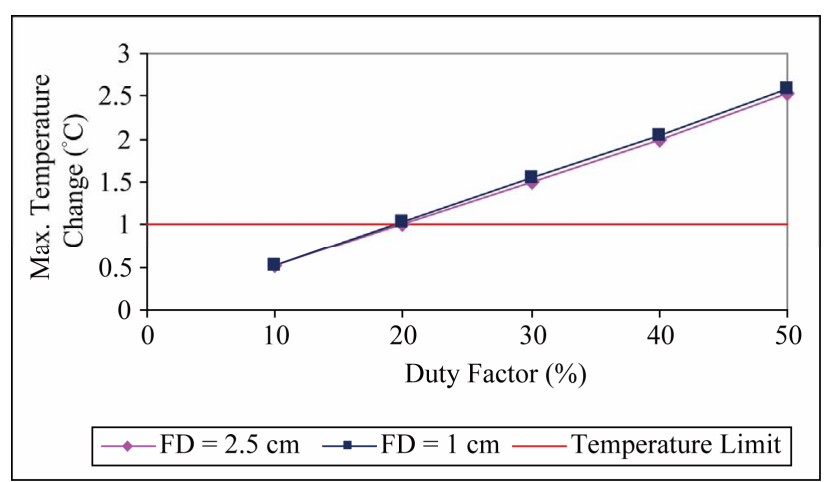

(b)

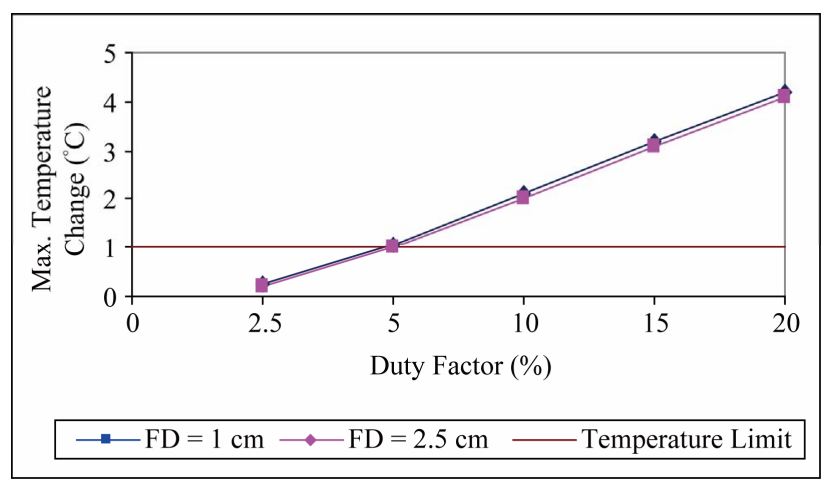

(d)

Figure 9. Temperature vs. duty factor for different power and F=0.5 MHz; (a) $2.5 \mathrm{~W}$, (b) $5 \mathrm{~W}$, (c) $10 \mathrm{~W}$, (d) $20 \mathrm{~W}$.

that if the focal depth is close to the skin $(1 \mathrm{~cm})$, then the temperature rises faster than when the focal depth is deeper $(2.5 \mathrm{~cm})$. This happens because the intensity is higher close to the surface and decreases as we go deeper into the tissue due to the attenuation and absorption coefficients. Figure 9 shows that when $0.5 \mathrm{MHz}$ frequency is used the difference in temperature elevation at the focal point of $1 \mathrm{~cm}$ and $2.5 \mathrm{~cm}$ is very small indicating that at lower frequencies the effect of focal depth is smaller compared to higher frequencies. Also, as the frequency increases from $0.5 \mathrm{MHz}$ to $1 \mathrm{MHz}$ (Figures 2 to 5) using the same intensity, the temperature elevation increases and therefore lower duty factor should be used to prevent heating above the maximum limit.

Finally, this simulation model is considered as a very useful tool for providing acoustic parameters (frequency, power, duty factor, pulse repetition frequency) during the application of pulse ultrasound at various depths in tissue so that safe temperature is maintained during the treatment.

\section{REFERENCES}

[1] Alexandrov, A.V., Molina, C.A., Grotta, J.C. et al. (2004) Ultrasoundenhanced systemic thrombolysis for acute ischemic stroke. New England Journal of Medicine, 351, 2170-2178. doi:10.1056/NEJMoa041175
[2] Maxwell, A.D., Owens, G., Gurm, H.S., Ives, K., Myers Jr, D.D. and Xu, Z. (2010) Noninvasive treatment of deep venous thrombosis using pulsed ultrasound cavitation therapy (histotripsy) in a porcine model. Journal of Vascular Interventional Radiology, 22, 369-377. doi:10.1016/j.jvir.2010.10.007

[3] Maxwell, A.D., Cain, C.A., Duryea, A.P., Yuan, L., Gurm, H.S. and $\mathrm{Xu}, \mathrm{Z}$. (2009) Noninvasive thrombolysis using pulsed ultrasound cavitation therapy-histotripsy. Ultrasound in Medicine and Biology, 35, 1982-1994. doi:10.1016/j.ultrasmedbio.2009.07.001

[4] Spengos, K., Behrens, S., Daffertshofer, M., Dempfle, C.E. and Hennerici, M. (2000) Acceleration of thrombolysis with ultrasound through the cranium in a flow model. Ultrasound in Medicine and Biology, 26, 889895.

[5] Eggers, J., König, I.R., Koch, B., Händler, G. and Seidel, G. (2008) Sonothrombolysis with transcranial colorcoded sonography and recombinant tissue-type plasminogen activator in acute middle cerebral artery main stem occlusion: Results from a randomized study. Stroke, 39, 1470-1475. doi:10.1161/STROKEAHA.107.503870

[6] Clement, G.T. (2004) Perspectives in clinical uses of high-intensity focused ultrasound. Ultrasonics, 42, 10871093. doi:10.1016/j.ultras.2004.04.003

[7] Li, C.-X., Xu, G.-L., Jiang, Z.-Y., Li, J.-J., Luo, G.-Y., Shan, H.-B., Zhang, R. and Li, Y. (2004) Analysis of clinical effect of high-intensity focused ultrasound on liver cancer. World Journal of Gastroenterol, 10, 22012204. 
[8] Damianou, C., Ioannides, K., Hadjisavvas, V., Milonas, N., Couppis, A. and Iosif, D. (2009) In vitro and in vivo brain ablation created by high intensity focused ultrasound and monitored by MRI. IEEE Transactions on Ultrasonics, Ferroelectrics and Frequency Control, 56, 1189-1198. doi:10.1109/TUFFC.2009.1160

[9] Kennedy, J.E. (2005) High-intensity focused ultrasound in treatment of solid tumors. Nature Reviews Cancer, 5, 321-327. doi:10.1038/nrc1591

[10] Zenitani, T., Suzuki, R., Maruyama, K. and Furuhata, H. (2008) Accelerating effects of ultrasonic thrombolysis with bubble liposomes. Journal of Medical Ultrasonics, 35, 5-10. doi:10.1007/s10396-007-0163-x

[11] Soltani, A., Prokop, A. and Vaezy, S. (2008) Stability of alteplase in presence of cavitation. Ultrasonics, 48, 109-116. doi:10.1016/j.ultras.2007.10.003

[12] Eggers, J., Ossadnik, S. and Seidel, G. (2009) Enhanced clot dissolution in vitro by $1.8-\mathrm{mhz}$ pulsed ultrasound. Ultrasound in Medicine and Biology, 35, 523-526. doi:10.1016/j.ultrasmedbio.2008.09.009

[13] Shaw, G., Meunier, J., Lindsell, C. and Holland, C. (2008) Tissue plasminogen activator concentration dependence of $120 \mathrm{khz}$ ultrasound-enhanced thrombolysis. Ultrasound in Medicine and Biology, 34, 1783-1792. doi:10.1016/j.ultrasmedbio.2008.03.020

[14] Saguchi, T., Onoue, H., Urashima, M., Ishibashi, T., Abe, T. and Furuhata, H. (2008) Effective and safe conditions of low-frequency transcranial ultrasonic thrombolysis for acute ischemic stroke: Neurologic and histologic evaluation in a rat middle cerebral artery stroke model. Stoke, 39, 1007-1011.

[15] Eggers, J., König, I.R., Koch, B., Händler, G. and Seidel, G. (2008) Sonothrombolysis with transcranial color-coded sonography and recombinant tissue-type plasminogen activator in acute middle cerebral artery main stem occlusion: Results from a randomized study. Stroke, 39, 1470-1475. doi:10.1161/STROKEAHA.107.503870

[16] Kim, Y.S., Rhim, H., Choi, M.J., Lim, H.K. and Choi, D. (2008) High-intensity focused ultrasound therapy: An overview for radiologists. Korean Journal of Radiology, 9, 291-302.

[17] Stone, M.J., Frenkel, V., Dromi, S., Thomas, P., Lewis, R.P., Li, K.C., Horne, M. 3rd and Wood, B.J. (2007) Pulsed-high intensity focused ultrasound enhanced tPA mediated thrombolysis in a novel in vivo clot model, a pilot study. Thrombosis Research, 121, 193-202.

doi:10.1016/j.thromres.2007.03.023

[18] Frenkel, V., Oberoi, J., Stone, M.J., Park, M., Deng, C., Wood, B.J., Neeman, Z., Horne, M. 3rd and Li, K.C. (2006) Pulsed high-intensity focused ultrasound enhances thrombolysis in an in vitro model. Radiology, 239, 86-93.

[19] Sapareto, S. and Dewey, W. (1984) Thermal dose determination in cancer therapy. International Journal of Radiation Oncology Biology Physics, 10, 787-800. doi:10.1016/0360-3016(84)90379-1

[20] Soneson, J.E. and Myers, M.R. (2007) Gaussian representation of high-intensity focused ultrasound beams. Journal of the Acoustical Society of America, 122, 2526-2531.

[21] Pennes, M. (1948) Analysis of tissue and arterial blood temperature in the resting human forearm. Journal of Applied Physiology, 1, 93-122.

[22] Holland, C.K., Vaidya, S.S., Datta, S., Coussios, C.-C. and Shaw, G.J. (2007) Ultrasoundenhanced tissue plasminogen activator thrombolysis in an in vitro porcine clot model. Thrombosis Research, 121, 663-673.

[23] Kornowski, R., Meltzer, R.S., Chernine, A., Vered, Z. and Battler, A. (1994) Does external ultrasound accelerate thrombolysis? Results from a rabbit model. American Heart Association, 89, 339-344.

[24] Nedelmann, M., Reuter, P., Walberer, M., Sommer, C., Alessandri, B., Schiel, D., Ritschel, N., Kempski, O., Kaps, M., Mueller, C., Bachmann, G. and Gerriets, T. (2008) Detrimental effects of $60 \mathrm{Khz}$ Sonothrombolysis in rats with middle cerebral artery occlusion. Ultrasound in Medicine and Biology, 34, 2019-2027. doi:10.1016/j.ultrasmedbio.2008.06.003

[25] Hynynen, K., Darkazanli, A., Unger, E. and Schenck, J. (1993) MRI-guided non-invasive ultrasound surgery. Medical Physics, 20, 107-115. doi:10.1118/1.597093

[26] Ishibashi, T., Akiyama, M., Onoue, H., Abe, T. and Furuhata, H. (2002) Can transcranial ultrasonication increase recanalization flow with tissue plasminogen activator? Stroke, 33, 1399-1404. doi:10.1161/01.STR.0000013789.15436.42 